\title{
Association of telomere instability with senescence of porcine cells
}

\author{
Guangzhen Ji', Kai Liu', Maja Okuka², Na Liu' and Lin Liư ${ }^{1,2 *}$
}

\begin{abstract}
Background: Telomeres are essential for the maintenance of genomic stability, and telomere dysfunction leads to cellular senescence, carcinogenesis, aging, and age-related diseases in humans. Pigs have become increasingly important large animal models for preclinical tests and study of human diseases, and also may provide xeno-transplantation sources. Thus far, Southern blot analysis has been used to estimate average telomere lengths in pigs. Telomere quantitative fluorescence in situ hybridization (Q-FISH), however, can reveal status of individual telomeres in fewer cells, in addition to quantifying relative telomere lengths, and has been commonly used for study of telomere function of mouse and human cells. We attempted to investigate telomere characteristics of porcine cells using telomere Q-FISH method.

Results: The average telomere lengths in porcine cells measured by Q-FISH correlated with those of quantitative real-time PCR method (qPCR) or telomere restriction fragments (TRFs) by Southern blot analysis. Unexpectedly, we found that porcine cells exhibited high incidence of telomere doublets revealed by Q-FISH method, coincided with increased frequency of cellular senescence. Also, telomeres shortened during subculture of various porcine primary cell types. Interestingly, the high frequency of porcine telomere doublets and telomere loss was associated with telomere dysfunction-induced foci (TIFs). The incidence of TIFs, telomere doublets and telomere loss increased with telomere shortening and cellular senescence during subculture.

Conclusion: Q-FISH method using telomere PNA probe is particularly useful for characterization of porcine telomeres. Porcine cells exhibit high frequency of telomere instability and are susceptible to telomere damage and replicative senescence.
\end{abstract}

Keywords: Telomere, Q-FISH, qPCR, Telomere doublets, Telomere dysfunction, Senescence

\section{Background}

Telomeres consist of (TTAGGG)n repeats and associated proteins at the end of chromosomes in mammalian cells and function in the maintenance of genomic stability to protect the chromosomes from degradation and end-toend fusion [1,2]. Telomere sequence is conserved among mammals $[3,4]$. Normal human cells, including the stem cells of renewal tissues, show progressive telomere shortening with cell division until a subset of telomeres reach a critically short length, inducing DNA-damage response and replicative senescence or cell aging [5-7].

\footnotetext{
*Correspondence: liutelom@yahoo.com

'State Key Laboratory of Medicinal Chemical Biology; College of Life Sciences, Nankai University, Tianjin 300071, China

${ }^{2}$ Department of Obstetrics and Gynecology, University of South Florida College of Medicine, Tampa, FL 33612, USA
}

Mouse cells may have telomere damage signaling pathways different from those of humans [8]. The observed senescence of mouse cells in culture may not be related to telomere shortening, but rather to changing culture condition, such as excessive oxidative stress [9]. It was proposed that the mouse may not be the best animal model for study of human telomere biology, as fundamental differences exist between human and mouse telomere biology [10]. Other mammals, including dogs, primates, and sheep, have also been compared for telomere biology and function [11-13]. Pigs have been considered as an ideal organ provider for xeno-transplantation and also as appropriate large animal models for preclinical tests and study of human diseases, including cardiovascular disease, diabetes, infectious disease, and cancer, and stem cell therapy [14-17], owing to the similarities in anatomy and physiology between pigs and humans [18]. Also, primary

\section{Biomed Central}

(c) 2012 Ji et al.; licensee BioMed Central Ltd. This is an Open Access article distributed under the terms of the Creative Commons Attribution License (http://creativecommons.org/licenses/by/2.0), which permits unrestricted use, distribution, and reproduction in any medium, provided the original work is properly cited. 
porcine cells have been genetically engineered to induce tumors in size similar to those observed clinically, and may provide a robust cancer model for preclinical studies [19].

Pig telomeres share the conserved TTAGGG sequence of mouse and human telomeres [20,21]. The terminal restriction fragments (TRFs) from pig cells $(9-50 \mathrm{~kb})$ are longer than those of human cells $(10-20 \mathrm{~kb})$ but shorter than those of laboratory mice $(30-200 \mathrm{~kb})[11,21]$. The major quantitative methods available for telomere measurement include length distribution of TRFs by Southern blot, quantitative fluorescence in situ hybridization (Q-FISH) that shows individual telomere lengths of metaphase spreads [22,23], mean telomere length by quantitative PCR (qPCR) [24,25], and PCR of single telomere lengths (STELA) [26]. Pig telomeres have been revealed by fluorescence in situ hybridization using human telomere repeat probe (TTAGGG)n [27] and primed in situ DNA synthesis (PRINS) [28], but telomere measurement by either method was not quantitative.

TRF measurement by Southern blot was employed to examine telomere lengths in cloned pigs [29,30]. TRFs show distribution of telomeres in smear gels by Southern blots, and only average telomere length is estimated by this approach. However, it is not the average telomere length but rather the shortest telomere that constitutes telomere dysfunction and that becomes a major determinant of the onset of senescence [31,32]. Consistently, chromosome arms carrying the shortest telomeres are the first to be unstable [33]. Telomeres were recently found to resemble fragile sites $[34,35]$. The shortest telomeres, or fragile telomeres, may reflect DNA-damage response signals in senescent human cells $[35,36]$. Thus far, quantitative measurement of telomeres at the level of individual chromosomes has not been performed in porcine cells. Moreover, the precise characteristics of pig telomeres and their roles in cellular senescence and immortalization remain elusive. We sought to measure pig telomeres by comparing three methods, Southern blot, Q-FISH, and qPCR, and to characterize pig telomeres in relevance to cellular senescence during subculture of pig primary cells.

\section{Results}

Telomere lengths shown as TRFs decrease during subculture of pig primary cells

Fibroblasts and mesenchymal cells derived from the bone marrow of fetal (embryonic day 50; abbreviated as FF and FM, respectively) and newborn (7 or 8 days old; NF and NM) pigs, as well as fibroblasts from adult pigs (3-4 months of age; AF), during their early passages, did not show significantly different telomere lengths (Figure 1A, B) by Southern blot analysis. Telomere lengths of newborn fibroblasts were slightly shorter than those of fetal

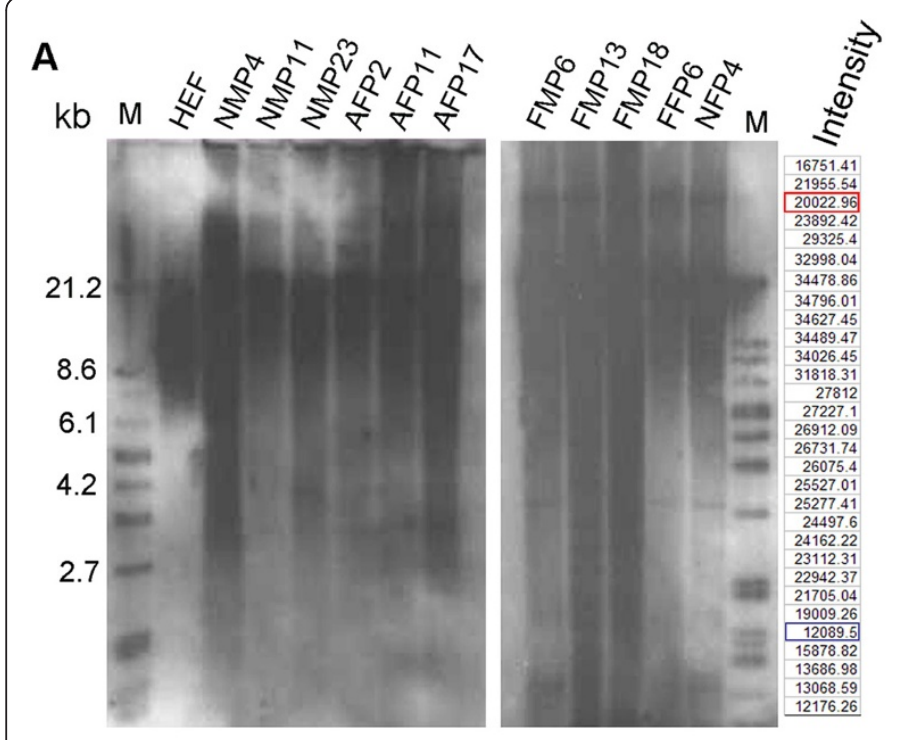

B

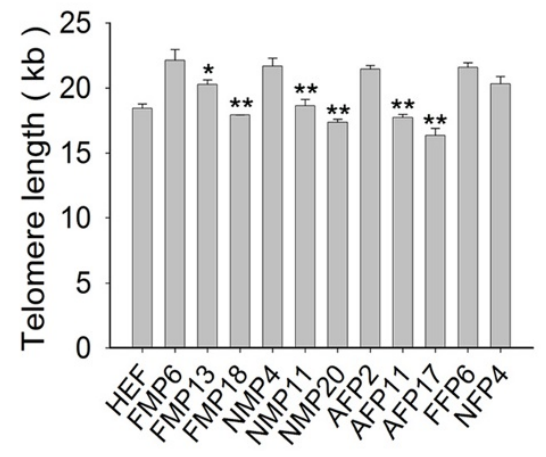

C

Noncanonical Subtelomeric region

Hinf I Rsal

-TCGACTCAAGTACTGC......-TTAGGG(TTAGGG)n

-AGCTGAGTTCATGACG......-AATCCC(AATCCC)n

Figure 1 Telomere length indicated as terminal restriction fragments (TRFs) by Southern blot analysis. (A) Distribution of telomere length as TRFs of various pig cell types. Each lane shows the intensity of TRF from different samples. At last 30 grids were scanned for each sample. Take HEF for example, "Intensity" indicates the scanned intensity of each grid. The Intensity in red and blue rectangle was used as threshold of the upper and lower background, and values above them for calculation of telomere length as detailed in Methods. FF and FM, fetal fibroblast and mesenchymal cells derived from embryonic day 50, respectively; NF and NM, newborn (7 or 8 days after birth) fibroblast and mesenchymal cells, respectively; AF, adult fibroblast from the ear skin of an adult pig, 3-4 months after birth; P, passage. (B) Average telomere lengths shown as TRFs in kilobase (kb) pairs of different cell types and changes in telomere lengths during passages. HEF, human embryonic fibroblasts. The data (mean \pm S.E.) was averaged from three independent experiments. ${ }^{*}, p<0.05 ;{ }^{*}, p<0.01$, compared to the earliest passage of the same cell types, by ANOVA analysis using Statview software. (C) Schematic representation of terminal restriction sites for digestion by enzyme combinations Hinfl and Rsal. 
fibroblasts during their early passages. Adult pig fibroblasts had telomere lengths similar to those of newborn fibroblasts. Telomere lengths of pig cells, regardless of the age of the animals, were longer than those of human fibroblasts (Figure 1A, B). The telomere lengths also were compared for fetal mesenchymal, newborn mesenchymal, and adult fibroblast cells during subcultures. Telomere lengths of these cells, shown as TRFs, shortened significantly $(\mathrm{p}<0.01)$ from early to late passages $(12-16$ passage intervals) (Figure 1B). The HinfI/RsaI restriction enzyme mixture was used for genome digestion, and telomeres were digested in the subtelomeric region (Figure 1C), such that TRFs contained lengths of various subtelomeric regions in the samples (Figure 1C). Therefore, measurements of telomeres by Southern blot analysis could show telomere TRF distribution, but the precise status of individual telomeres was not discernible.

Telomere doublets and signal-free ends increase during subculture of pig cells identified by Q-FISH

To further confirm the TRF results obtained by Southern blot analysis and to analyze individual telomeres, we measured telomere lengths of the pig cell types described above by metaphase telomere Q-FISH using FITC-labeled (CCCTAA) PNA probe. Telomeres, at both terminal and interstitial sites, were found in various pig cell types (Figure 2A). Notably, telomere doublets were typically found at high frequencies at the chromosome ends of all cell types examined (Figure 2A, B). In contrast, only fewer doublets $(\sim 0.5 \%)$ were observed in mouse embryonic fibroblasts (MEFP3). Consistent with the TRF data, the average relative telomere lengths estimated by Q-FISH did not differ among pig cell types (Figure 2A, B). Not all telomere doublets were clearly separated by the fluorescence signal, so the mean telomere length measured by Q-FISH also contained the signal of the doublets. Fluorescence of one doublet often exhibited a lower signal intensity than the other of the sister doublets. Pig cells during early passages showed a low frequency of telomere signal-free ends $(\sim 0.5 \%)$, indicative of telomere loss (Figure $2 \mathrm{~B})$. Compared to mouse embryonic fibroblasts (Figure 2C, D), pig cells showed shorter telomeres and higher frequency of telomere doublets. Moreover, pig cells, after more passages (FMP18, NMP20, AFP17) during subculture, exhibited telomere shortening, compared to their primary cells (FMP6, NMP4 and AFP2) during the early (7-9) passages (Figure 3A). Interestingly, telomeres shortened less at later passages in these cells (Figure 3A, B, Figure 1B). Telomeres are maintained primarily by active telomerase $[1,31]$. We determined telomerase activity in various cell types using TE ELISA Kit. Telomerase activity of pig mesenchymal cells and fibroblast cells were detectable (Figure 3C). The telomerase activity of fetal and newborn pig mesenchymal cells did not show noticeable decrease during passages, whereas the activity in adult pig fibroblasts declined during passages. Reduced telomerase activity coincided with evident telomere shortening and loss in adult fibroblasts during passages (Figure 3A, B). Yet, the telomerase activity seemed not to correlate with telomere shortening and loss in newborn mesenchymal cells, and the reason is unclear presently.

During subculture of various pig cell types, frequencies of telomere signal-free ends and doublets increased, accompanied by telomere shortening (Figure 3D, E). High frequency of telomere signal-free ends seemed to coincide with higher incidence of telomere doublets in pig cells.

\section{Telomere length measurement by quantitative real-time PCR}

An additional method was required to further confirm the data obtained by Q-FISH. We showed that both qPCR and Q-FISH methods complement each other for telomere measurement in mouse cells [37]. Initial experiments were designed to determine whether human and/or mouse telomere primers could efficiently amplify pig telomeres by qPCR (Figure 4A). Pig 36B4 was used as an internal control. Samples for both mouse and human telomeres and 36B4 amplification were run under the same conditions. We found that primers for mouse telomeres $(\mathrm{mTel})$ were suitable for pig telomere amplification, based on amplification efficiency and melting curves (Figure 4A, B), whereas pig telomere amplification efficiency using human telomere primers was only $60.9 \%$ (Figure 4C). In addition, 35 ng of DNA was suitable for amplification of both pig telomeres and 36B4 (Figure 4C).

By qPCR analysis, telomeres from five cell types showed similar lengths, with relatively shorter telomeres in adult fibroblasts (Figure 5A), consistent with the results obtained by Southern and Q-FISH methods. Further, telomeres shortented in pig fetal mesenchymal cells, newborn mesenchymal cells, and adult fibroblasts from early to late passages $(\mathrm{p}<0.01)$ (Figure 5A). Regression analysis indicated that the average telomere lengths measured by Southern, Q-FISH, and qPCR were highly $(\mathrm{P}<0.001)$ correlated with each other, showing high $\mathrm{R}^{2}$ between Q-FISH and Southern, $\mathrm{qPCR}$ and Southern, and Q-FISH and $\mathrm{qPCR}$ as $0.84,0.66$ and 0.80 , respectively (Figure $5 \mathrm{~B}$ ).

\section{Increased telomere dysfunction with accumulation of senescent cells}

We speculated that telomere shortening and dysfunction are associated with cell senescence in pig cells during passaging. Cellular senescence was evaluated by standard $\beta$-galactosidase ( $\beta$-Gal) assay (Figure 6A). Indeed, the incidence of $\beta$-Gal-positive cells increased remarkably with increasing passages, regardless of the cell types (Figure 6B). Senescence can be triggered by up-regulation of $p 53$ and 

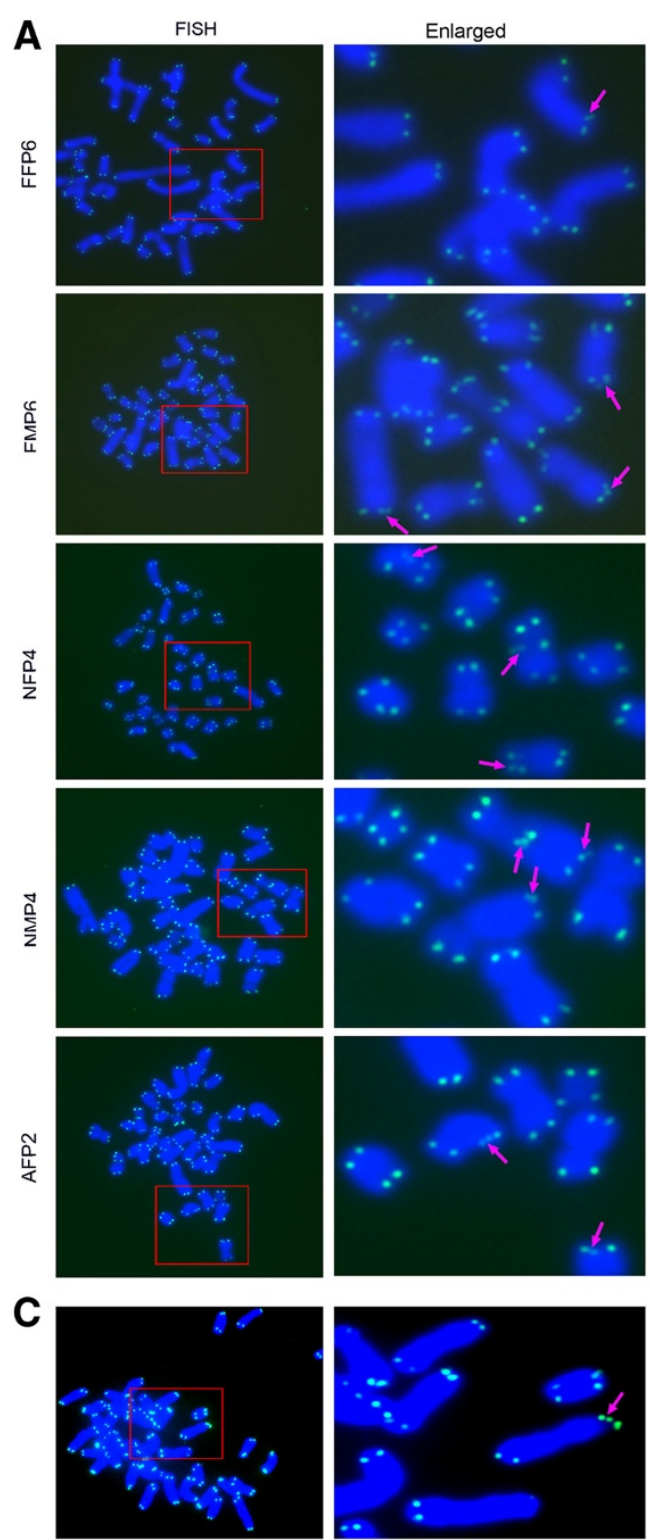

B
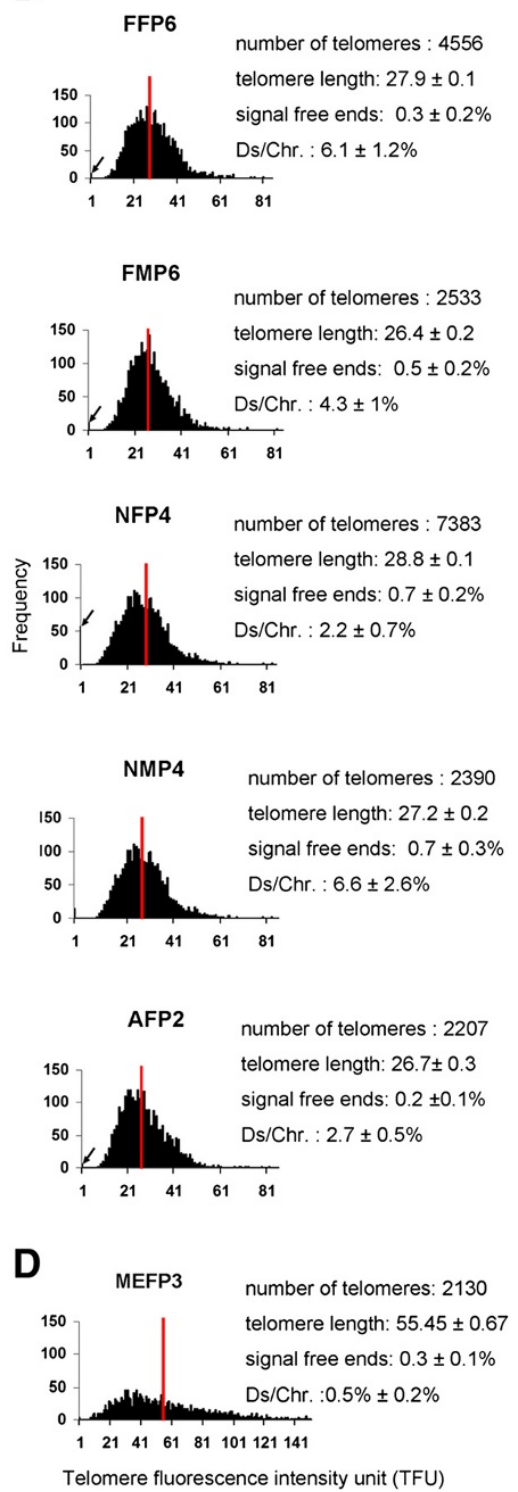

Figure 2 Telomere length and structure analysis by telomere quantitative fluorescence in situ hybridization (Q-FISH). (A) Representative images of telomere Q-FISH in pig cells. Red rectangle, enlarged region shown in the right column. FF and FM, fetal fibroblast and mesenchymal cells derived from fetus at embryonic day 50, respectively; NF and NM, newborn (7 or 8 days after birth) fibroblast and mesenchymal cells, respectively; AF, adult fibroblasts from the ear skin of an adult pig, 3-4 months after birth. P, passages. Enlarged views: Blue, DAPI-stained chromosomes. Green dots, telomeres; Purple arrows, telomere doublets; P, passage. (B) Histogram shows distribution of relative telomere length shown as telomere fluorescence intensity unit (TFU) in pig cells. Medium telomere length is shown as mean TFU \pm SE. The medium telomere length (red bars) is also shown as mean \pm SE in the upper right hand corner. Ds, telomere doublets; Chr, chromosomes. Black arrows on the Y-axis indicate frequency of telomere signal-free ends. (C) Representative image of mouse telomeres (green) by Q-FISH. Enlarged view at right. Blue, chromosomes. (D) Telomere distribution and length of mouse embryonic fibroblast at passage 3 (MEFP3).

p21 [38], and p53-dependent senescence responds to dysfunctional telomeres [38,39]. Consistently, expression levels of $p 53$ and $p 21$ increased during subculture of pig cells (Figure 6C), in association with telomere shortening. Changes in 553 protein levels were verified by Western blot (Figure 6D). $\gamma$-H2AX foci colocalized with telomeres, as indicative of telomere dysfunction-induced foci (TIFs)
[40], were analyzed for various cell types. The percentage of TIFs by IF-FISH and of cells with DNA damage increased significantly at later passages (Figure 6E, F).

\section{Discussion}

We compared three methods for telomere measurement in pig cells. Using telomere Q-FISH method [23,41], 
A
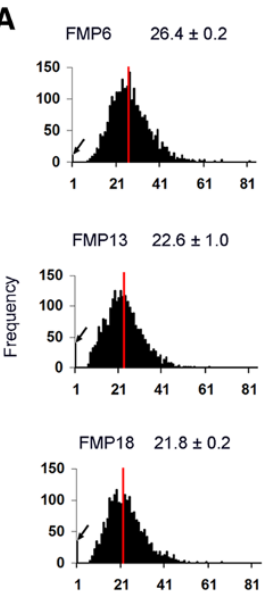
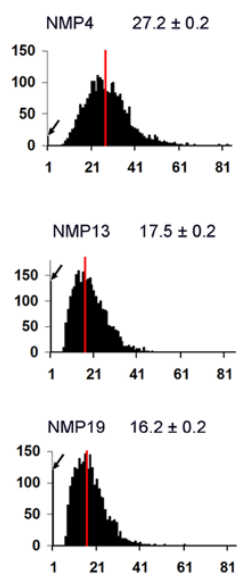

Telomere fluorescence intensity unit (TFU)
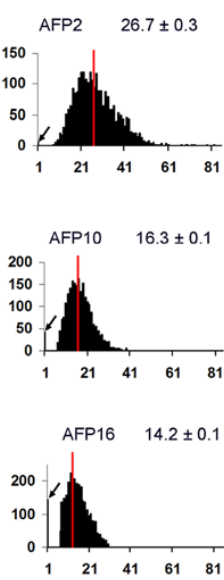

C
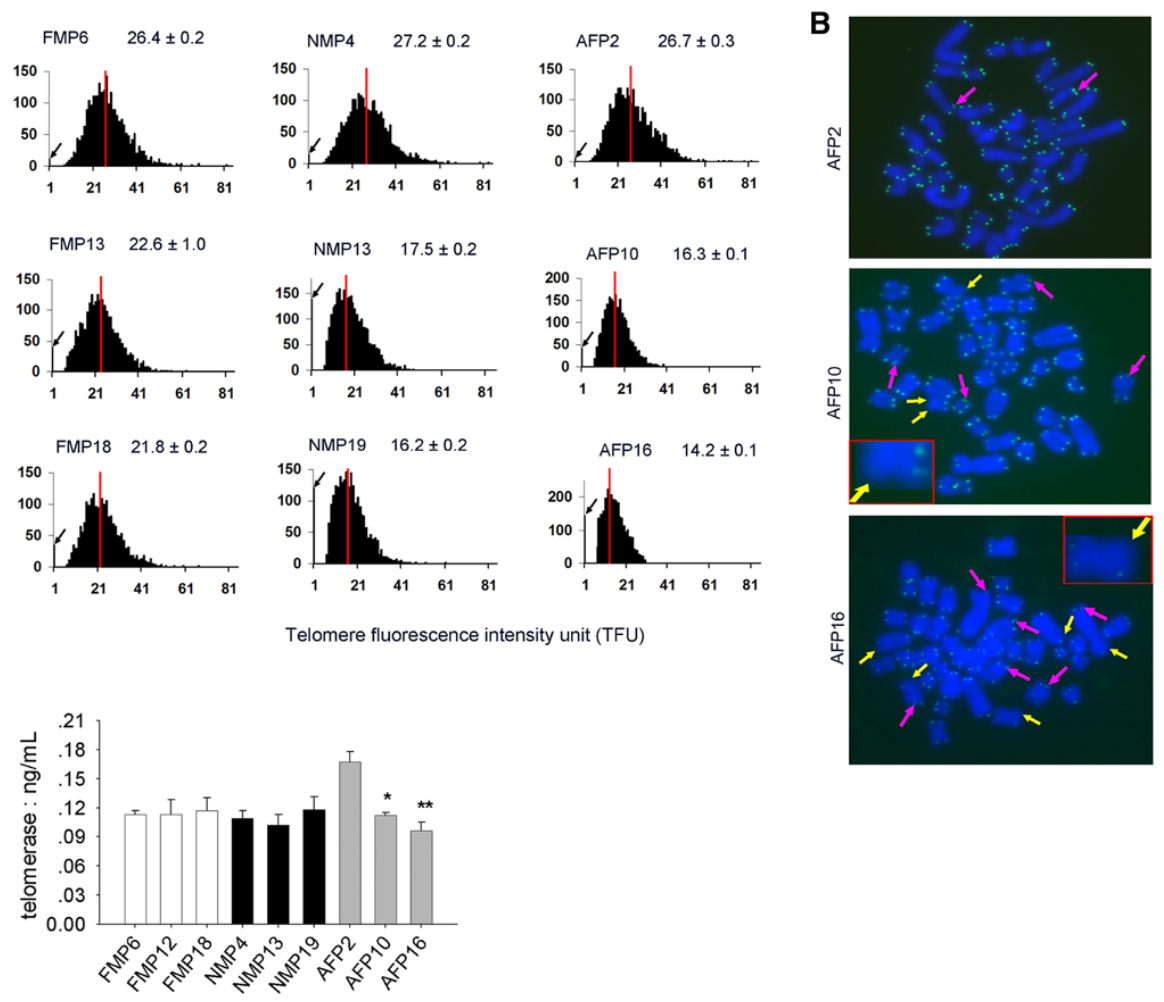

D

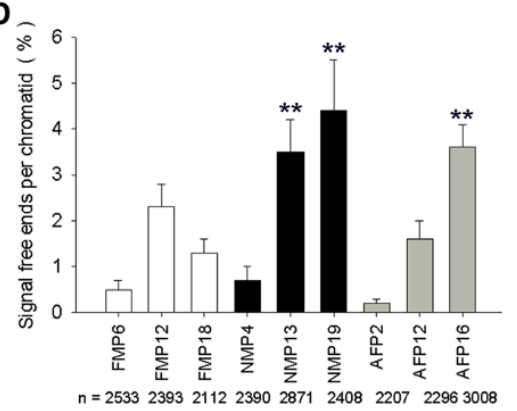

E

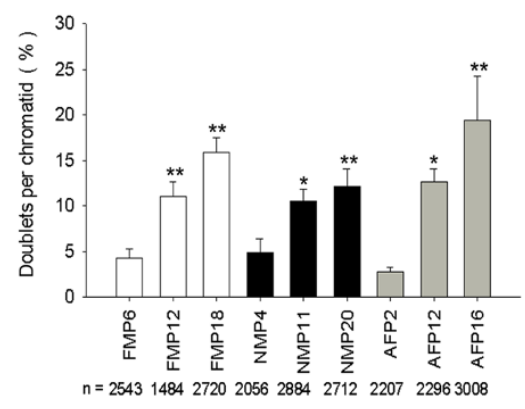

Figure 3 Telomere length by metaphase Q-FISH analysis of various porcine cell types during subculture. (A) Telomere distribution and length from various pig cells during subculture. The medium telomere length (red bars) is also shown as mean \pm SE in the upper right hand corner. Black arrows on the Y-axis indicate frequency of telomere signal-free ends. (B) Representative image of adult fibroblasts (AF) during subculture from early to late passage. Purple arrows, telomere doublets; Yellow arrows, telomere signal-free ends. (C) Quantification of telomerase activity of various pig cell types by ELLSA. ${ }^{*}, p<0.05 ;{ }^{*}, p<0.01$, compared to the earliest passage of the same cell type. (D) Frequency of telomere signal-free ends in 3 types of pig cells during subculture; $n$, number of telomeres counted; \%, number of signal-free ends per chromatid. (E) Percentage of telomere doublets in 3 pig cell types during subculture; \%, number of doublets per chromatid. ${ }^{*}, p<0.05$; **, $p<0.01$, compared to the earliest passage.

interestingly, we found that pig cells show high incidence of telomere doublets. Pig lymphocytes at metaphase were analyzed by FISH with telomeric DNA probes to identify telomeres at both terminal and interstitial sites, but the method was not sensitive enough to reveal telomere doublets [27]. Telomeres in interphase nuclei of pig ovarian follicles were also measured by FISH with telomeric DNA probes [42], but the overlapping of telomere signals in interphase nuclei might overestimate the telomere signals. We show here that the Q-FISH method using telomeric PNA probe is very useful in determining both the lengths and the status of pig telomeres.

Telomere qPCR yields T/S ratio and is a time-saving method for relative quantitative measurement of telomeres. In addition, the method only requires a small amount of sample [24,25]. We slightly modified the telomere amplification conditions by amplification of both telomere and 36B4 primers in one set of reaction. We found a high correlation of $\mathrm{T} / \mathrm{S}$ ratio measured by $\mathrm{qPCR}$ with telomere length measured by Q-FISH in mouse stem 


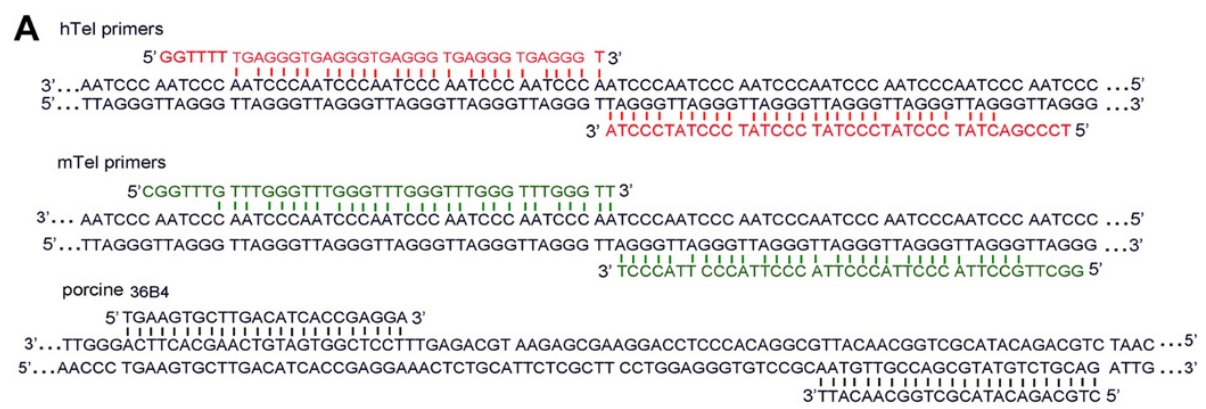

B
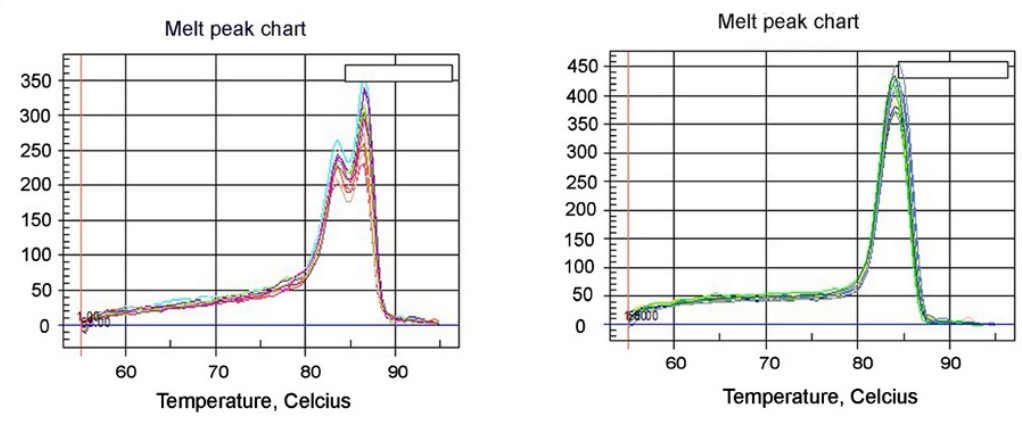

C

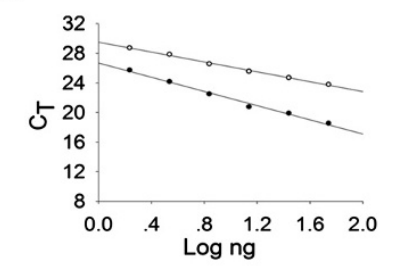

- $h$ Tel $E=60.9 \% R^{2}=0.984$ Slope $=-4.84$

- $36 \mathrm{~B} 4 \mathrm{E}=98.9 \% \mathrm{R}^{2}=0.995$ Slope $=-3.35$

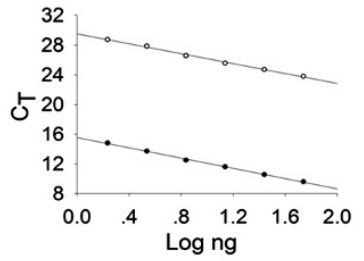

- $\quad m$ Tel $E=104.3 \% R^{2}=0.986$ Slope $=-3.22$

- $36 \mathrm{~B} 4 \mathrm{E}=98.9 \% \mathrm{R}^{2}=0.995$ Slope $=-3.35$

Figure 4 Optimization of telomere measurement of pig cells by quantitative real-time PCR analysis (qPCR). (A) Telomere primers for pig telomere amplification and 36B4 primers. Telomere primers for human and mouse telomere measurement by qPCR were described previously $[23,24]$. (B) Melting curve charts of human telomere primers and mouse telomere primers for pig telomere analysis, respectively. (C) Standard curves for pig telomere amplification, using human telomere primers and porcine 36B4, mouse telomere primers and porcine 36B4, respectively. Telomeres and 36B4 for standard curves were derived by serial dilution of a known quantity of genomic DNA isolated from spleen cells. hTel,

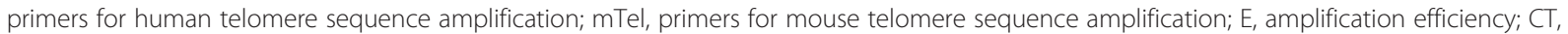
threshold cycle. Solid circle, telomeres; Hollow circle, 36B4 control.

cells [37]. The T/S ratio determined by qPCR contained lengths of both terminal and interstitial telomere sequences. Interestingly, telomeric primers for mouse, but not human telomeres, are suitable for pig telomere measurement by qPCR. The reason is unclear, but might relate to higher amplification efficiency for longer telomeres of pig cells. Together, telomere lengths measured by three methods showed strong correlation, proving effective measurement of relative telomere lengths by each method. Telomere structure, loss, and doublets, however, can only be revealed by Q-FISH method.

Telomere lengths of pig skin fibroblasts at early passages show no appreciable differences among individuals. Yet, telomeres shorten significantly during subculture of various pig cell types. Also, human fibroblasts undergo replicative senescence, accompanied by accumulation of short telomeres and loss of telomeric sequences $[6,38,43]$, and the accumulated telomeric loss accelerates senescence [44]. Up-regulation of $p 53$ and $p 53$-induced gene, $p 21$, is associated with cell senescence $[38,45,46]$. Likewise, porcine cells show increased expression levels of $p 53$ and $p 21$, along with telomere shorting and cell senescence. Telomere dysfunction, accompanied by cell senescence, has been shown to appear early in human cells $[38,47]$. It appears that pig cells undergo senescence in a manner similar to human cells.

Notably, pig cells exhibit telomere doublets at a high incidence. Primary pig cell lines showed approximately 

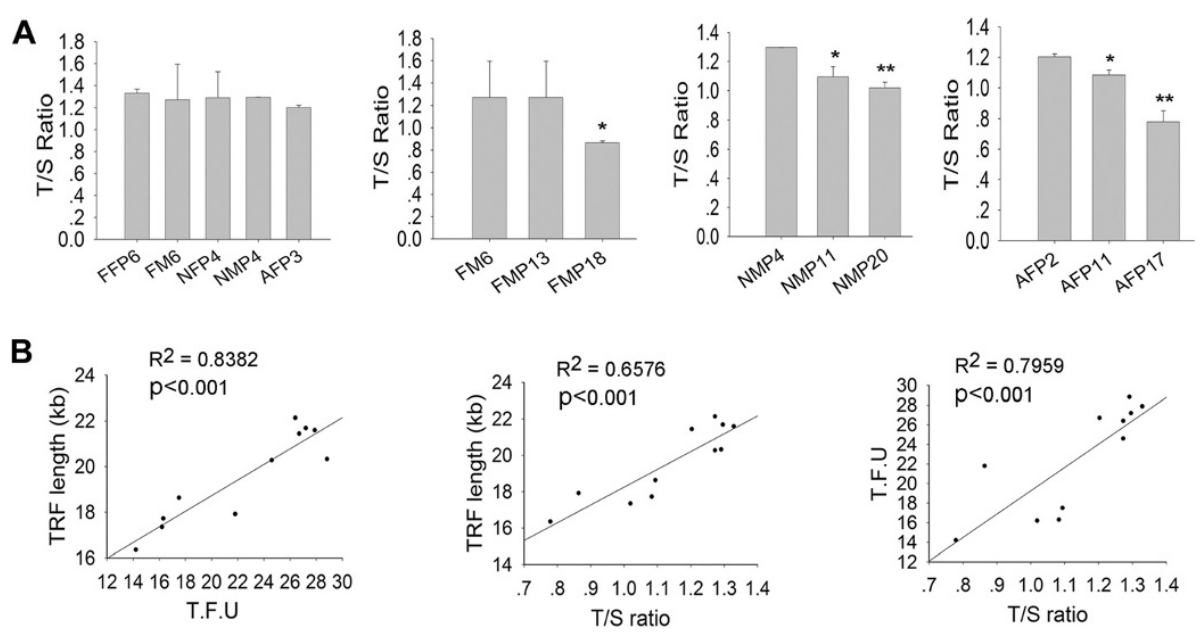

Figure 5 Telomere measurements of pig cells shown as a T/S ratio by qPCR and its correlation with TRFs, and TFU by Q-FISH. (A) Average relative telomere length shown as T/S ratios of various cell pig cells and during passage by $\mathrm{QPCR}$ method. T, telomere; $\mathrm{S}, 36 \mathrm{~B} 4$ singlecopy gene. P, passage. * $p<0.05$; **, $p<0.01$, compared to the earliest passage. (B) Correlation of telomere length between TFU by Q-FISH, $\mathrm{T} / \mathrm{S}$ ratio by $\mathrm{qPCR}$, and TRFs $(\mathrm{kb})$ by Southern blot.

5\% doublets, similar to human cells [48]. Telomere doublets often refer to more than one telomeric signal at a single chromatid end [49]. Telomere doublets may indicate fragile telomeres, following damages to telomeres [49-52]. Telomere doublets are indicative of genome instability. Telomere doublets are found in both normal and mutant human cells [48], and also associated with fragile telomeres and cellular senescence [34,53]. Increased frequency of telomere doublets during subculture of pig cells also coincides with telomere loss and dysfunction, in association with cellular senescence. Both telomere doublets and telomere loss represent telomere instability, and telomere doublets may lead to telomere shortening and loss under stress conditions. Telomere doublets may provide a marker for cell senescence.

\section{Conclusion}

Porcine cells exhibit high frequency of telomere doublets and are susceptible to telomere damage and replicative senescence. Telomere biology of pigs appears to be similar to that of humans. Investigation of telomere dysfunction and senescence using pig cells may complement studies of human biology and medicine.

\section{Methods}

\section{Cell culture}

The use of the animals for this research was approved by the Institutional Animal Care and Use Committee at Nankai University. Porcine (Yorkshire) fibroblasts from fetal (embryonic day 50), newborn (7 or 8 days after birth), and adult (3-4 months) pigs were isolated by a standard tissue-attachment method. The upper layer of pig ear skin was removed, and the remaining tissue was minced into $1 \times$ $1-\mathrm{mm}^{3}$ pieces, placed to culture dishes, and incubated in Dulbecco's Modified Eagle Medium (DMEM)(Gibico, USA), containing 10\% fetal bovine serum (FBS)(Thermo, USA). Gelatinous bone marrow tissues from fetal femurs and tibias, at embryonic day 50, as well as from newborn piglets were extracted under sterile conditions. Bones were rinsed with DMEM after both ends were cut. The recovered cells were centrifuged, resuspended, and plated in culture dishes. The culture medium containing 15\% FBS, was changed every other day, and cells passaged every 3 or 4 days when the cells reached $90 \%$ confluence. Human fibroblasts (HEF) were provided by Z. Liu at Sun Yat-Sen University.

\section{Chromosome spreads and telomere Q-FISH}

Cells were incubated with $0.2-0.3 \mu \mathrm{g} / \mathrm{mL}$ nocodazole (Sigma, St. Louis, MO, USA) for $3 \mathrm{~h}$ to enrich the cells in metaphase. Chromosome spreads for different cell types were made using a routine method. Metaphase-enriched cells were subjected to hypotonic treatment in a $75 \mathrm{mM}$ $\mathrm{KCl}$ solution, fixed with methanol:glacial acetic acid (3:1), and spread onto clean slides. Telomere FISH and quantification were performed as described previously [22,23,41], except that a fluorescein isothiocyanate (FITC)-labeled (CCCTAA) peptide nucleic acid (PNA) probe was used in this study. Telomeres were denatured at $80^{\circ} \mathrm{C}$ for $3 \mathrm{~min}$ and hybridized with telomere PNA probe $(0.5 \mu \mathrm{g} / \mathrm{mL})$ (Panagene, Daejeon, Korea). Chromosomes were stained with $0.5 \mu \mathrm{g} / \mathrm{mL}$ 4',6-diamidino-2-phenylindole (DAPI). Fluorescence signals from chromosomes and telomeres were digitally imaged using a Zeiss microscope with FITC/DAPI filter sets, in combination with AxioCam and AxioVision software 4.6. For quantitative measurement of 

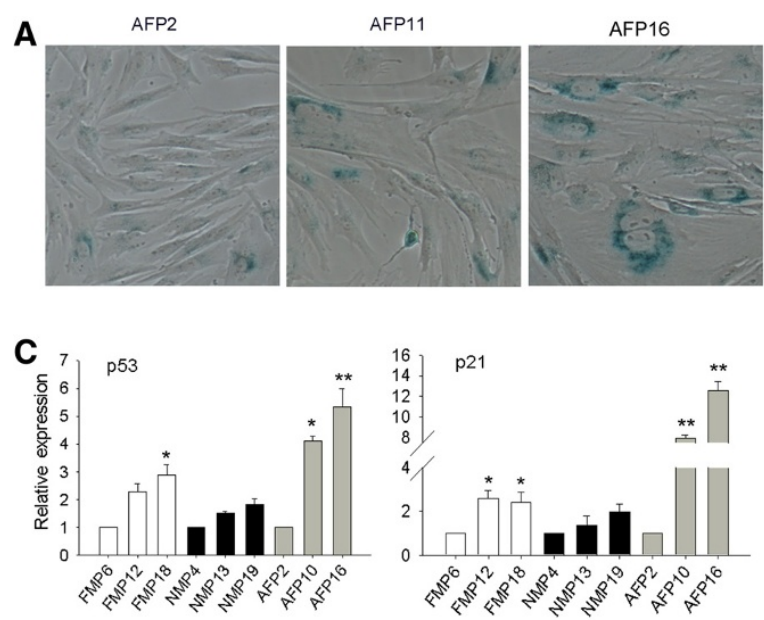

E
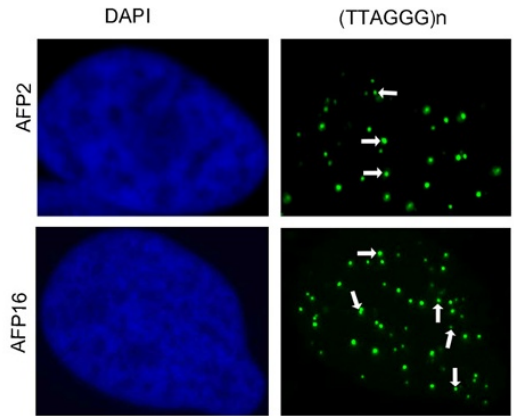

$\mathbf{F}$
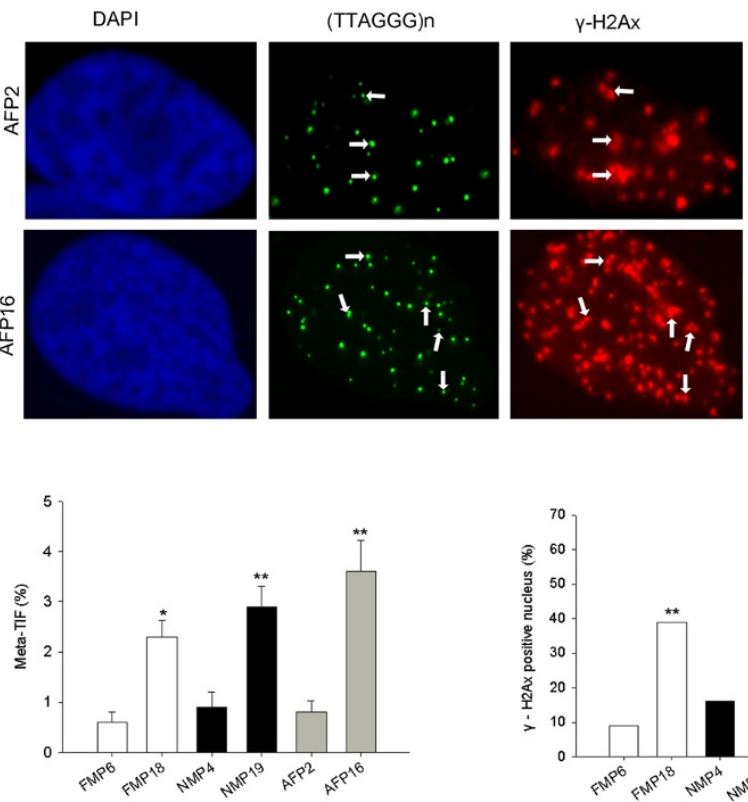

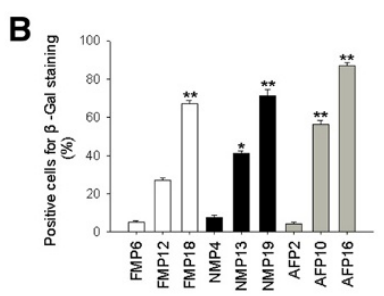

D

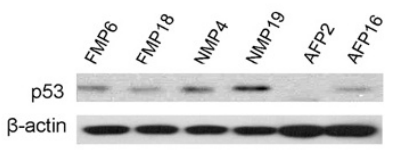

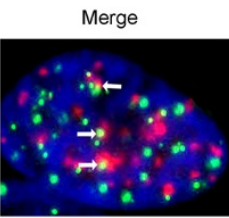
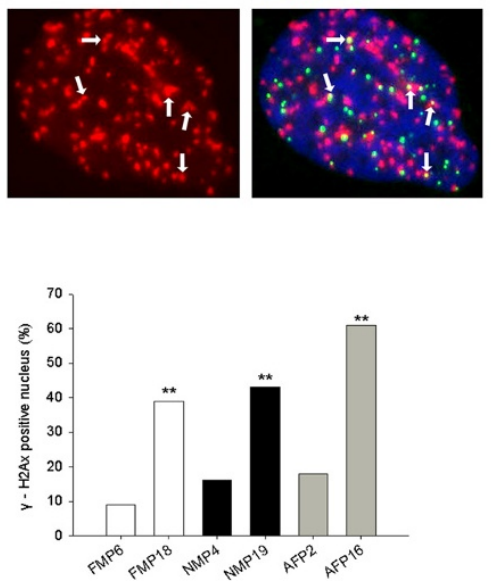

Figure 6 Telomere dysfunction is associated with cellular senescence in pig cells. (A) Morphology of adult fibroblasts (AF) during subculture by $\beta$-galactosidase staining. P, passage. Senescent cells are stained blue. (B) Quantification of senescent cells positive for $\beta$-galactosidase staining. (C) Relative expression levels by qPCR of the senescence-related genes, $p 53$ and p21, in 3 types of pig cells during subculture. ${ }^{*}, p<0.05{ }^{* *}, p<0.001$, compared to the primary cells at the earliest passage. (D) P53 protein levels in different cell lines from early to late passages by immuno-blot analysis. $\beta$-actin served as loading control. (E) Representative images showing TIFs as DNA damage foci (white arrows) indicated by $\gamma$-H2AX foci at telomeres by IF-FISH. Nuclei, blue; Telomere, green; $\gamma$-H2AX, red. (F) Percentage of TIFs and $\gamma$-H2AX-positive nucleus in various pig cell types. In all, 100 cells were counted for each cell line. ${ }^{*}, \mathrm{p}<0.05$; ${ }^{*}, \mathrm{p}<0.01$, compared to the early passage of the same cell type.

telomere length, telomere fluorescence intensity was integrated using the TFL-TELO program (a gift kindly provided by P. Lansdorp, Terry Fox Laboratory, Vancouver, Canada). More than 15 metaphase spreads were examined for each cell type.

Telomere measurement by quantitative real-time PCR A modified qPCR method by amplification of both telomeres and the single-copy gene (36B4) within one set of reactions proves to be effective for measurement of telomere length in early embryonic and pluripotent stem cells in mice $[37,54]$. DNA samples were extracted from various cell types using the DNeasy Blood \& Tissue Kit (Qiagen, Valencia, CA, USA). The average telomere length was measured from total genomic DNA using a real-time PCR assay, as previously described [24,25,37], with slight modifications for measurement of pig telomeres using human or mouse telomere primers: human 
telomeric primers $\left(5^{\prime}-3^{\prime}\right)$ : (hTel) Forward, GGTTTTTG AGGGTGAGGGTGAGGGTGAGGGTGAGGGT; hTel Reverse, TCCCGACTATCCCTATCCCTATCCCTATC CCTATCCCTA; murine telomere (mTel) Forward, CG GTTTGTTTGGGTTTGGGTTTGGGTTTGGGTTTG GGTT; mTel Reverse, GGCTTGCCTTACCCTTACC CTTACCCTTACCCTTACCCT. Primers for the reference control gene (pig 36B4 single-copy gene): forward, TGAAGTGCTTGACATCACCGAGGA; reverse, CTGCAGACATACGCTGGCAACATT. The PCR amplification system for telomeres included a SYBR Green Mix of $12.5 \mu \mathrm{L}, 400 \mathrm{nM}$ forward and reverse telomere primers. The reaction system for the 36B4 gene contained the same amount of SYBR Green mix as telomeres, 400 $\mathrm{nM}$ forward primer and $640 \mathrm{nM}$ reverse primer. Samples with equal amounts ( $35 \mathrm{ng}$ ) of DNA were added to 2 adjacent wells. A sufficient quantity of double-distilled water was added to each well to yield a final volume of $25 \mu \mathrm{L}$. Both telomeres and the 36B4 gene were amplified under the same conditions. For each PCR reaction, a standard curve was made by serial dilution of known amounts of DNA. All PCR reactions were performed using iCycler iQ real-time PCR detection system (Bio-Rad, Hercules, CA, USA). Pig spleen DNA diluted from 110 to $1.7 \mathrm{ng}$ was amplified for the standard curve. The telomere $(\mathrm{T})$ signal was normalized to the signal from the single-copy (S) gene to generate a $\mathrm{T} / \mathrm{S}$ ratio indicative of relative telomere length. Equal amounts of DNA (35 ng) were used for each reaction, with at least 3 replicates for each specimen.

\section{Terminal restriction fragment (TRF) assay}

Genomic DNA from the different samples was prepared as above and DNA was dissolved in nuclease-free water. The DNA quality was assayed using a spectrophotometer, and the ratio of 260 to 280 was between 1.8 and 2.1. The mean telomere length was determined by mean TRF length analysis using TeloTAGGG Telomere Length Assay Kit (Roche, Mannheim, Germany), according to the protocol provided by the manufacturer, with slight modifications. Each DNA sample $(3 \mu \mathrm{g})$ was digested with HinfI and RsaI overnight. The digested DNA was separated by agarose gel $(0.8 \%)$ electrophoresis at $5 \mathrm{~V} / \mathrm{cm}$ in $1 \times \mathrm{TBE}$ buffer for $4 \mathrm{~h}$. Gels were denatured, neutralized, and transferred to positively charged nylon membranes (Amersham, Oakville, ON, Canada) overnight. The membranes were prehybridized in DIG Easy Hyb (Roche) at $42^{\circ}$ $\mathrm{C}$ for $45 \mathrm{~min}$, and then hybridized in DIG Easy Hyb containing the telomere probe at $42^{\circ} \mathrm{C}$ for $3 \mathrm{~h}$. The membranes were washed, blocked, and incubated with Anti-DIG-AP working solution and detection buffer. They were then subjected to chemiluminescence detection according to the manufacturer's instructions and exposed to X- ray film for 1-5 min. The mean telomere length was calculated using the following formula: $\operatorname{TRF}=\Sigma\left(O D_{i}\right) / \Sigma\left(O D_{i} / L_{i}\right)$, where $\mathrm{OD}_{\mathrm{i}}$ is the chemiluminescent signal and $\mathrm{OD}_{\mathrm{i}} / \mathrm{L}_{\mathrm{i}}$ is the length of the TRF at position $\mathrm{i}$.

\section{Gene expression analysis by quantitative real-time PCR}

Total RNA was isolated from porcine cells by using an RNeasy mini kit (Qiagen). RNA $(2 \mu \mathrm{g})$ was subjected to cDNA synthesis using M-MLV Reverse Transcriptase (Invitrogen, Grand Island, NY, USA). Real-time quantitative PCR reactions were set up in duplicate with the SYBR Green Master (TOYOBO) and run on the iCycler iQ5 2.0 Standard Edition Optical System (Bio-Rad). Each sample was repeated 3 times and analyzed with $\beta$-actin as the internal control. Most primers were designed using the IDT DNA website (http://www.idtdna.com/ Home/Home.aspx) as follows: $p 21$ forward, 5 ACCATG TGGACCTGTTGCTGT3', and reverse, $5^{\prime}$ AGAAATCT GTCATGCTGGTCTGCC3'; $p 53$ forward, 5/GGAACA GCTTTGAGGTGCGTGTTT3', and reverse, 5'AATAC TCGCCATCCAGTGGCTTCT3'; $\beta$-actin forward, $5^{\prime}$ TG CGGCATCCACGAAACTAC3', and reverse, 5'TTCTG CATCCTGTCGGCGAT3'.

\section{Senescence $\beta$-galactosidase staining}

Cells were stained using a senescence kit (Beyotime, C0602, Shanghai, China), according to the manufacturer's instructions. Cells were fixed with formalin for 15 min at room temperature, washed with PBS 3 times, and incubated at $37^{\circ} \mathrm{C}$ with $\beta$-galactosidase working solution overnight. Samples were mounted, and imaged under a microscope (ECLITSE-TS100, Nikon, Japan). At least 5 pictures were randomly captured for each sample. More than 10,000 cells were counted for quantification of senescent cells.

\section{Western blot analysis}

The P53 protein expression levels were analyzed for cultured pig cells at early and late passages. Primary antibody against P53 (sc-126, Santa Cruz) was used for Western blotting and $\beta$-actin (P30002, abmart) served as loading controls. Cells were lysed in lysis buffer plus $1 \mathrm{mM}$ PMSF. Protein concentration was quantified by Pierce $^{\circledR}$ BCA Protein Assay Kit (23227 Thermo). The protein samples $(20 \mu \mathrm{g})$ were separated on $10 \%$ SDSpolyacrylamide gels and transferred to a PVDF membrane $(0.2 \mu \mathrm{m}$ Millipore ISEQ00010). After blocking with TBST buffer containing 5\% nonfat dry milk, the membrane was incubated with the primary antibodies. After washing and incubation with secondary antibody (ECL anti-rabbit/mouse IgG, NA934/NA931 GE Healthcare), the proteins were detected using chemiluminescent HRP substrate reagent (WBKLS0100, Millipore). 


\section{Telomerase activity assay}

Telomerase activity of pig cells was quantified using TE ELISA Kit (CSB-E06793p, CUSABIO, China) according to the manufacturer's protocol. $1 \times 10^{6}$ cells in $300 \mu \mathrm{l}$ PBS were used for telomerase quantification, and $100 \mu \mathrm{l}$ Standard, Blank, or Sample added per well, covered with the adhesive strip, and incubated for $2 \mathrm{~h}$ at $37^{\circ} \mathrm{C}$. Biotinantibody working solution $(100 \mu \mathrm{l})$ was added to each well and incubated for $1 \mathrm{~h}$ at $37^{\circ} \mathrm{C}$. After washing for three times, $100 \mu \mathrm{l}$ HRP-avidin working solution was added to each well, covered with a new adhesive strip, and incubated for $1 \mathrm{~h}$ at $37^{\circ} \mathrm{C}$. After washing, $90 \mu \mathrm{l} \mathrm{TMB}$ Substrate was added to each well, and incubated for $15-30 \mathrm{~min}$ at $37^{\circ} \mathrm{C}$. The optical density of each well was determined using a microplate reader set to $450 \mathrm{~nm}$.

\section{Telomere dysfunction induced foci (TIFs) by immunofluorescence (IF)-telomere FISH (IF-FISH)}

IF-FISH was performed as described previously [34,40]. Briefly, cells were grown on gelatin-treated cover slips and fixed with $2 \%$ paraformaldehyde for $10 \mathrm{~min}$ at room temperature. The cells were washed with a blocking solution $(1 \mathrm{mg} / \mathrm{mL}$ bovine serum albumin, $3 \%$ goat serum, $0.1 \%$ Triton X 100 and $1 \mathrm{mM}$ EDTA pH 8.0) and incubated with anti- $\gamma \mathrm{H} 2 \mathrm{AX}$ (Upstate, 05-636, CA) in blocking solution. The secondary antibody against mouse IgG was labeled with Alexa Flour 594 (Invitrogen). Cells were fixed in $2 \%$ paraformaldehyde for $5 \mathrm{~min}$, and FISH was performed using a FITC-(CCCTAA) $)_{3}$ PNA telomere probe (Panagene), as described above. DNA was counterstained with $0.5 \mu \mathrm{g} / \mathrm{L}$ DAPI in Vectashield mounting medium (Vector Laboratories, Burlingame, CA). Fluorescence was detected and imaged using a Zeiss Imager Z1 microscope equipped with an epifluorescence source and lenses.

\section{Statistical analysis}

Percentages were transformed using arcsine transformation. Transformed percentage data and other numbers were analyzed by analysis of variance (ANOVA), and means were compared by Fisher's protected leastsignificant difference (PLSD) test using StatView software from SAS Institute Inc. (Cary, NC). Linear relationships and regression analysis were performed using SigmaPlot 8.0 (Systat Software, San Jose, CA, USA). Significant differences were defined as $\mathrm{p}<0.05,0.01$, or lower.

\section{Competing interest}

The authors declare that they have no competing interests.

\section{Authors' contributions}

$\mathrm{GJ}, \mathrm{KL}, \mathrm{MO}$, NL performed experiments and data analysis. GJ designed the experiments and wrote the manuscript; $L L$ designed and advised the experiments, and revised manuscripts. All authors read and approved the manuscript.

\section{Acknowledgements}

This work was supported by MOST National Major Basic Research Program (2009CB941000 and 2011CBA01002).

Received: 21 February 2012 Accepted: 10 December 2012

Published: 15 December 2012

\section{References}

1. Blackburn EH: Switching and signaling at the telomere. Cell 2001, 106:661-673.

2. Palm W, de Lange T: How shelterin protects mammalian telomeres. Annu Rev Genet 2008, 42:301-334

3. Moyzis RK, Buckingham JM, Cram LS, Dani M, Deaven LL, Jones MD, Meyne J, Ratliff RL, Wu JR: A highly conserved repetitive DNA sequence, (TTAGGG)n, present at the telomeres of human chromosomes. Proc Natl Acad Sci USA 1988, 85:6622-6626.

4. Meyne J, Ratliff RL, Moyzis RK: Conservation of the human telomere sequence (TTAGGG)n among vertebrates. Proc Natl Acad Sci USA 1989, 86:7049-7053.

5. Allsopp RC, Vaziri H, Patterson C, Goldstein S, Younglai EV, Futcher AB, Greider CW, Harley CB: Telomere length predicts replicative capacity of human fibroblasts. Proc Natl Acad Sci USA 1992, 89:10114-10118.

6. Harley $C B$, Futcher $A B$, Greider $C W$ : Telomeres shorten during ageing of human fibroblasts. Nature 1990, 345:458-460.

7. Wright WE, Shay JW: Historical claims and current interpretations of replicative aging. Nature Biotechnol 2002, 20:682-688.

8. Smogorzewska A, de Lange T: Different telomere damage signaling pathways in human and mouse cells. EMBO J 2002, 21:4338-4348.

9. Parrinello S, Samper E, Krtolica A, Goldstein J, Melov S, Campisi J: Oxygen sensitivity severely limits the replicative lifespan of murine fibroblasts. Nature Cell Biol 2003, 5:741-747.

10. Wright WE, Shay JW: Telomere dynamics in cancer progression and prevention: fundamental differences in human and mouse telomere biology. Nat Med 2000, 6:849-851.

11. Davis T, Kipling D: Telomeres and telomerase biology in vertebrates: progress towards a non-human model for replicative senescence and ageing. Biogerontology 2005, 6:371-385.

12. Davis T, Skinner JW, Faragher RG, Jones CJ, Kipling D: Replicative senescence in sheep fibroblasts is a p53 dependent process. Exp Gerontol 2005, 40:17-26.

13. Brummendorf TH, Mak J, Sabo KM, Baerlocher GM, Dietz K, Abkowitz JL, Lansdorp PM: Longitudinal studies of telomere length in feline blood cells: implications for hematopoietic stem cell turnover in vivo. Exp Hematol 2002, 30:1147-1152.

14. Cozzi E, Bosio E, Seveso M, Rubello D, Ancona E: Xenotransplantation as a model of integrated, multidisciplinary research. Organogenesis 2009, 5:288-296.

15. Giraud S, Favreau F, Chatauret N, Thuillier R, Maiga S, Hauet T: Contribution of large pig for renal ischemia-reperfusion and transplantation studies: the preclinical model. J Biomed Biotechnol 2011, 2011:532127.

16. Whyte JJ, Prather RS: Genetic modifications of pigs for medicine and agriculture. Mol Reprod Dev 2011, 78:879-891.

17. Adam SJ, Counter CM: A method to generate genetically defined tumors in pigs. Methods Enzymol 2008, 439:39-51.

18. Samstein B, Platt JL: Physiologic and immunologic hurdles to xenotransplantation. J Am Soc Nephrol 2001, 12:182-193.

19. Adam SJ, Rund LA, Kuzmuk KN, Zachary JF, Schook LB, Counter CM: Genetic induction of tumorigenesis in swine. Oncogene 2007, 26:1038-1045.

20. Kipling D, Cooke HJ: Hypervariable ultra-long telomeres in mice. Nature 1990, 347(6291):400-402

21. Fradiani PA, Ascenzioni F, Lavitrano M, Donini P: Telomeres and telomerase activity in pig tissues. Biochimie 2004, 86:7-12.

22. Zijlmans JM, Martens UM, Poon SS, Raap AK, Tanke HJ, Ward RK, Lansdorp PM: Telomeres in the mouse have large inter-chromosomal variations in the number of T2AG3 repeats. Proc Natl Acad Sci USA 1997, 94:7423-7428.

23. Herrera E, Samper E, Martin-Caballero J, Flores JM, Lee HW, Blasco MA: Disease states associated with telomerase deficiency appear earlier in mice with short telomeres. EMBO J 1999, 18:2950-2960.

24. Callicott RJ, Womack JE: Real-time PCR assay for measurement of mouse telomeres. Comp Med 2006, 56:17-22. 
25. Cawthon RM: Telomere measurement by quantitative PCR. Nucleic Acids Res 2002, 30:e47.

26. Baird DM, Rowson J, Wynford-Thomas D, Kipling D: Extensive allelic variation and ultrashort telomeres in senescent human cells. Nat Genet 2003, 33:203-207.

27. de la Sena C, Chowdhary BP, Gustavsson I: Localization of the telomeric (TTAGGG)n sequences in chromosomes of some domestic animals by fluorescence in situ hybridization. Hereditas 1995, 123:269-274.

28. Wnuk M, Bugno M, Slota E: Application of primed in situ DNA synthesis (PRINS) with telomere human commercial kit in molecular cytogenetics of equus caballus and Sus scrofa scrofa. Folia histochemica et cytobiologica / Polish Academy of Sciences, Polish Histochemical and Cytochemical Society 2008, 46:85-88.

29. Jiang $L$, Carter DB, $X u$ J, Yang $X$, Prather RS, Tian $X C$ : Telomere lengths in cloned transgenic pigs. Biol Reprod 2004, 70:1589-1593.

30. Jeon HY, Hyun SH, Lee GS, Kim HS, Kim S, Jeong YW, Kang SK, Lee BC, Han JY Ahn $C$, et al: The analysis of telomere length and telomerase activity in cloned pigs and cows. Mol Reprod Dev 2005, 71:315-320.

31. Hemann MT, Strong MA, Hao LY, Greider CW: The shortest telomere, not average telomere length, is critical for cell viability and chromosome stability. Cell 2001, 107:67-77.

32. Abdallah P, Luciano P, Runge KW, Lisby M, Geli V, Gilson E, Teixeira MT: A two-step model for senescence triggered by a single critically short telomere. Nature Cell Biol 2009, 11:988-993.

33. der-Sarkissian H, Bacchetti S, Cazes L, Londono-Vallejo JA: The shortest telomeres drive karyotype evolution in transformed cells. Oncogene 2004, 23:1221-1228.

34. Sfeir A, Kosiyatrakul ST, Hockemeyer D, MacRae SL, Karlseder J, Schildkraut CL, de Lange T: Mammalian telomeres resemble fragile sites and require TRF1 for efficient replication. Cell 2009, 138:90-103.

35. McNees CJ, Tejera AM, Martinez P, Murga M, Mulero F, Fernandez-Capetillo $\mathrm{O}$, Blasco MA: ATR suppresses telomere fragility and recombination but is dispensable for elongation of short telomeres by telomerase. J Cell Biol 2010, 188:639-652

36. Meier A, Fiegler H, Munoz P, Ellis P, Rigler D, Langford C, Blasco MA, Carter N, Jackson SP: Spreading of mammalian DNA-damage response factors studied by ChIP-chip at damaged telomeres. EMBO J 2007, 26:2707-2718.

37. Huang J, Wang F, Okuka M, Liu N, Ji G, Ye X, Zuo B, Li M, Liang P, Ge WW, et al: Association of telomere length with authentic pluripotency of ES/ iPS cells. Cell Res 2011, 21:779-792.

38. Herbig U, Jobling WA, Chen BP, Chen DJ, Sedivy JM: Telomere shortening triggers senescence of human cells through a pathway involving ATM, p53, and p21(CIP1), but not p16(INK4a). Mol Cell 2004, 14:501-513.

39. Flores I, Blasco MA: A p53-dependent response limits epidermal stem cell functionality and organismal size in mice with short telomeres. PLoS One 2009, 4:e4934

40. Takai H, Smogorzewska A, de Lange T: DNA damage foci at dysfunctional telomeres. Curr Biol 2003, 13:1549-1556.

41. Poon SS, Martens UM, Ward RK, Lansdorp PM: Telomere length measurements using digital fluorescence microscopy. Cytometry 1999, 36:267-278.

42. Russo V, Berardinelli P, Martelli A, Di Giacinto O, Nardinocchi D, Fantasia D, Barboni B: Expression of telomerase reverse transcriptase subunit (TERT) and telomere sizing in pig ovarian follicles. J Histochem Cytochem 2006, 54:443-455

43. Martens UM, Chavez EA, Poon SS, Schmoor C, Lansdorp PM: Accumulation of short telomeres in human fibroblasts prior to replicative senescence. Exp Cell Res 2000, 256:291-299.

44. Noel JF, Wellinger RJ: Abrupt telomere losses and reduced end-resection can explain accelerated senescence of Smc5/6 mutants lacking telomerase. DNA Repair 2011, 10:271-282.

45. Bringold F, Serrano M: Tumor suppressors and oncogenes in cellular senescence. Exp Gerontol 2000, 35:317-329.

46. Ramirez RD, Herbert BS, Vaughan MB, Zou Y, Gandia K, Morales CP, Wright WE, Shay JW: Bypass of telomere-dependent replicative senescence (M1) upon overexpression of Cdk4 in normal human epithelial cells. Oncogene 2003, 22:433-444.

47. Kaul Z, Cesare AJ, Huschtscha LI, Neumann AA, Reddel RR: Five dysfunctional telomeres predict onset of senescence in human cells. EMBO Rep 2011, 13:52-59.
48. Philippe C, Coullin P, Bernheim A: Double telomeric signals on single chromatids revealed by FISH and PRINS. Ann Genet 1999, 42:202-209.

49. Mitchell TR, Glenfield K, Jeyanthan K, Zhu XD: Arginine methylation regulates telomere length and stability. Mol Cell Biol 2009, 29:4918-4934.

50. d'Adda di Fagagna F, Reaper PM, Clay-Farrace L, Fiegler H, Carr P, Von Zglinicki T, Saretzki G, Carter NP, Jackson SP: A DNA damage checkpoint response in telomere-initiated senescence. Nature 2003, 426:194-198.

51. Wang RC, Smogorzewska A, de Lange T: Homologous recombination generates T-loop-sized deletions at human telomeres. Cell 2004, 119:355-368.

52. van Overbeek M, de Lange T: Apollo, an Artemis-related nuclease, interacts with TRF2 and protects human telomeres in $\mathrm{S}$ phase. Curr Biol 2006, 16:1295-1302.

53. Martinez P, Thanasoula M, Munoz P, Liao C, Tejera A, McNees C, Flores JM, Fernandez-Capetillo O, Tarsounas M, Blasco MA: Increased telomere fragility and fusions resulting from TRF1 deficiency lead to degenerative pathologies and increased cancer in mice. Genes Dev 2009, 23:2060-2075.

54. Liu L, Bailey SM, Okuka M, Munoz P, Li C, Zhou L, Wu C, Czerwiec E, Sandler $L$, Seyfang A, et al: Telomere lengthening early in development. Nature Cell Biol 2007, 9:1436-1441.

doi:10.1186/1471-2121-13-36

Cite this article as: Ji et al:: Association of telomere instability with senescence of porcine cells. BMC Cell Biology 2012 13:36.

\section{Submit your next manuscript to BioMed Central and take full advantage of:}

- Convenient online submission

- Thorough peer review

- No space constraints or color figure charges

- Immediate publication on acceptance

- Inclusion in PubMed, CAS, Scopus and Google Scholar

- Research which is freely available for redistribution 